\title{
Effect of Personalized Learning on Mathematics Performance among Secondary Schools in Awendo Sub-County, Kenya
}

\author{
Peter Ogwari, Prof. Elizabeth Mendoza-Role, PhD and Catherine Amimo, PhD \\ School of Education, Humanities and Social Sciences University of Eastern Africa, Baraton, Kenya \\ ${ }^{*}$ Corresponding author: kogwari@gmail.com
}

\begin{abstract}
This study explored the effect of Personalized Learning (PL) on mathematics performance, based on the Social Constructivism Theory of Learning. Purposive sampling was used to select one school with 40 form one students taught by one teacher. Data collection techniques used included video recording and photos, observation schedules, questionnaires and achievement examination. Data was analyzed using descriptive statistics (mean, standard deviation) and Mann-Whitney $U$ Test. Findings revealed that both the experimental and control group, with 20 students per group, had same level of achievement before PL was implemented. The Posttest showed that the experimental class had a higher performance index than the control at $74.15 \%$ against $68.95 \%$. With a $p$ value of $0.957>0.05$, the difference between the posttest scores of the experimental group and the control group was considered not significant. The p-value of $0.594>0.05$ also indicated that posttest scores of the male and female students in the experimental group is not significant. The implementation was generally good for Student Ownership and Reflection $(M=3.21 ; S D=0.49)$, areas of Targeted Instruction $(M=2.92 ; S D=0.69)$, Flexible Content Tools and Learning Environment $(M=2.86 ; S D=0.64520$. However, inconsistency was observed mostly in the implementation of PL which focused on group work, student's interests, needs, skill level and one on one support. The study recommends that Mathematics teachers should be inducted in PL particularly in the use of Flexible Content Tools and Learning Environment that factors in student's interests, needs, skill level and support.
\end{abstract}

Key words: Personalized Learning, Performance, Mathematics, Secondary School

\section{Introduction}

Personalized System of Instruction is an approach that customizes learning for each student, tapping on students' goals, interests, needs and abilities in relation to the curriculum. It addresses values and fosters logical thinking skills particularly in science and mathematics (De Freitas \& Yapp, 2005). It relies on proper identification of students' responses to a given problem and making necessary alteration, while specifying contingencies/ misconceptions between the responses and the expected feedback. According to Pane, Steiner, Baird, Hamilton, and Pane (2017, p. 2),

Personalized learning prioritizes a clear understanding of the needs and goals of each individual student and the tailoring of instruction to address the needs and goals. These needs and goals, and progress towards meeting them are highly visible and easily assessable to teachers as well as students and their families, are frequently discussed among these parties and are updated accordingly.

Personalized learning is characterized by learners' learning at different stations and setting with little intervention from the teacher. Learners are allowed to move from one station to the next upon mastering the work at hand or rather the unit in question (Deakin, 2007).

Personalized learning should not be confused with individualized learning. Whereas individualized learning places the focus on the teacher planning 
tasks for individuals who in turn work as individual elements on the assigned tasks, personalized learning involves the teacher focusing on what different individuals can contribute to effective learning for the whole class. Several studies show that such initiatives in personalized learning result in better test scores and outcomes for students. What is perhaps most exciting and equally daunting is the potential for personalized learning to evolve what it means to be a good methodology (De Freitas \& Yapp, 2005).

The $21^{\text {st }}$ century is the threshold that leads educationists to divert from the traditional classroom initiatives to contemporary initiatives that make the classroom learning situations more dynamic. One of these initiatives is personalizing the instruction which is referred to as the effort on the part of a school to take into account individual student characteristics and needs and flexible instructional practices in organizing the learning environment. Teachers committed to personalizing instruction help their students develop personal learning plans, assist in diagnosing their cognitive strengths and weaknesses and other style characteristics, help adapt the learning environment and instruction to learners' needs and interests and impart authentic and reflective learning experiences for their students (Demski, 2012).

\section{Components of Personalized Learning}

Personalized learning encompasses a variety of programs that aim at addressing different learning needs and interests of students from diverse backgrounds. Concomitantly, students' search for understanding motivates them to learn better. The following components of personalized learning were examined; student choice, student engagement, flexible learning environment and personal learning paths (McLeskey, Rosenberg \& Westling, 2017). When students want to know more about an idea, a topic, or an entire discipline, they put more cognitive energy into classroom investigations and discussions and study more on their own. Thus, the elements of the teaching-learning process must be flexible yet interactive in a constructive learning environment (Bolstad et al., 2012).

A survey report on an attempt to introduce personalized learning strategy in Australian secondary schools revealed that there was a marked improvement in as much as there were ongoing challenges facing the implementation of personalized learning such as time factor, resources and evaluation procedures (Prain et al., 2013). This gap paved ways for investigation about personalized leaning in other countries like Kenya.

\section{Personalized Learning and Student's Achievement}

In a report developed under a grant from the US Department of Education, researchers noted the potential for personalized learning structures to improve student outcomes. Furthermore, the report noted that based on the evidence from evaluations of high school reform models, creating a personalized and orderly learning environment was an area in which successful interventions contributed to improved high school student outcomes, particularly in large high schools (Herlihy \& Quint, 2006).

A study that analyzed performance data from 36,000 United States of American students that used personalized learning in the school year 20162017, show a strong growth in reading, math and other academic measures. Students achieved an average growth of $130 \%$ in reading and $122 \%$ in math on the NWEA MAP exam. Fifty-seven percent of those students met or exceeded the reading growth target while $61 \%$ met or exceeded the math growth target. Additionally, ninety-two percent of district leaders said teachers were more effective in using the personalized learning approach while $70 \%$ of teachers were confident that personalized learning has a positive effect on teaching and learning (cited in Osadebe \& Nwabeze, 2018).

In India, tens of thousands of students use the cloud-based application Mindspark to learn math and language It is an Al-powered personalized adaptive learning tool that curates a tailored learning path for students, based on the information generated by an individual student's responses to questions and activities. It then adjusts the type and difficulty of content delivered as per the child's need, style and pace of learning. The key difference of Mindspark from other online test applications is that it uses big data and machine learning to identify patterns in the way students answer questions. If the software picks up a student's weaknesses, it recommends remedial exercises (Rajendran \& Muralidharan, 2013).

Cheaper mobile devices coupled with the boom in educational app development results to many learners in developing countries accessing quality educational media outside the classroom (Papadakis 
\& Kalogiannakis, 2017). An increase in the use of technology (especially in Nigeria and South Africa) has enabled educational technology to broaden, taking learning to students' daily commutes and homes. Technology in Africa enables teachers, parents and learners to share knowledge and develop stronger educational frameworks. Mobile phones do streamline and improve education administration and communication among stakeholders (Traxler \& Leach, cited in Traxler, 2016).

ReKindle Learning, founded by ed-tech entrepreneur Rapelang Rabana, works to improve education in Africa using technology. One tool ReKindle has developed is KnowledgeFox which Rekindle describes as an adaptive learning tool that ensures personalized reinforcement of learning in a wide range of academic learning areas (Lionesses of Africa, n.d.). Another effective technological learning venture is Rethink Education. Mobile learning tools by Rethink include an app that provides Mathematics and Science support. With such technology, learners are able to work through the full high school Mathematics and Science curriculum and educators can also customize existing app frameworks to serve their educational institutions' needs (Criticos, 2000).
Today, schools are faced with many problems including lack of skilled and passionate teachers, outdated curriculum, ill-equipped facilities that house more students than they should and much more. In Nigeria, for, example, the failing education system is evident where $70 \%$ of graduates from tertiary institutions are unemployable (Fafunwa, 2018). In-spite of students' trending approaches to personalized learning using modern technology like the case in India, Nigeria and even Kenya, most teachers are stuck with teacher-centered methods which do not support the learning of Mathematics (Rajendran \& Muralidharan, 2013; Traxler, 2016).

While the Kenya Vision 2030 (aiming to transform Kenya into a newly industrialized middle-income economy) focuses on technology related subjects such as mathematics, persistent failures in the subject has remained a major concern (Yara \& Otieno, 2010). Learners continue to manifest weak understanding of mathematical concepts, skills generalization, among others, not only in external examinations but also in classroom exercises (Bot, cited in Babayemi \& Olagunjo, 2015). This view is supported by the Kenya Examination Council report of the year 2017 on the Kenya Certificate of Secondary Education (KNEC, 2017) which recorded very low percentage passes in Mathematics where $50 \%$ of the candidates got a mean grade of " $E$ ".

Table 1: Mathematics Mean Score in KCSE Alt B (2013-2017)

\begin{tabular}{llllll}
\hline Year & 2013 & 2014 & 2015 & 2016 & 2017 \\
\hline Mean Score & $17.29 \%$ & $24.76 \%$ & $16.58 \%$ & $17.18 \%$ & $20.20 \%$ \\
\hline
\end{tabular}

Adopted from KNEC (2017)

From table 1 , it is noted that the mean score of mathematics across the five-year period from 2013 to 2017 is below $25 \%$. It is therefore imperative that mathematics teachers improve their teaching methods in order to assist students to improve performance in mathematics. Therefore, this study sought to fill this gap by determining the effect of personalized learning on the performance of Mathematics among Secondary schools in Awendo, Kenya.

\section{Research Methodology}

This section presents the methodology that guided the study.

\section{Research Design}

This study employed a quantitative research approach which quantifies the problem by generating numerical data that can be transformed into usable statistics. Quantitative research approach is the standard experimental method of most scientific disciplines (Shuttleworth, 2008).

Specifically, this study adopted a quasi-experimental design (pretest-posttest control group design) (Mertler \& Charles, 2008). Prior to the implementation of the treatment, participants in the two groups were as identical as possible on the following variables; mean entry mark, boy- girl ratio, participants per class and most importantly being taught by one teacher. The experimental group was taught using the personalized learning strategies such as flipping the classrooms and helping students to set short and long term goals which were followed by tracking their progress according to how they have prioritized their work. This group was allowed to learn content at their own pace even as they reflected on what they had learnt. The control group, on the other hand, was taught using 
traditional patterns whereby they listened to lectures and took notes, quizzes and tests.

\section{Population and Sampling}

A Form one class of 40 students in a private mixed secondary school of a total population of 240 students was purposively selected because the foundation for secondary mathematics is laid at this level, and the topics of experimentation were derived from form one syllabus. The 40 form one students were divided into two streams of twenty each by randomization of their entry behavior.

\section{Data Collection Instruments}

Research instruments used in the study included lesson plan analysis guide, achievement examination, questionnaire and classroom observation schedule. A lesson plan was the teacher's detailed description of the course of instruction for a lesson. It was developed daily to guide the teacher in class teaching and learning. Achievement examination which was given to students comprised of 20 questions derived from the topics that were covered during the experimentation period. The questions ranged from simple to complex bearing in mind the Bloom's taxonomy and was guided by tables of specifications. The achievement test was administered before the treatment (pretest) and after the treatment (posttest). The questionnaire which was used to collect data on the implementation of personalized learning in the experimental group adopted a four - point scale of Agree (4), Tend to agree (3), Tend to disagree (2) and Disagree (1). According to Nunnaly (cited in Schutt (2017), it is suggested that one should use somewhere from 4 to 11 points on a rating scale. Further, it is suggested that omitting the middle alternative (e. g. neutral, about the same, average, no difference), which is the case in this study, does not appreciably affect the overall pattern of results (Schuman \& Presser, cited in Schutt, 2017, p. 202). In addition, a classroom observational schedule was used to monitor how the lessons in the experimental group were progressing based on the personalized learning model. It was composed of a learning activity; time allocated for each activity, frequency of the activity and a reflection on the lesson.

\section{Statistical Treatment of Data}

Data was analyzed using descriptive statistics where means and standard deviations were calculated to find out the level of achievement in mathematics by the students in the experimental and control groups as well as the implementation of personalized learning method. Mann-Whitney $U$ test, which is a non-parametric test, was used to compare the achievement of students in the control and experimental groups. This was because the sample size was small and therefore not satisfying the distributional requirements of parametric methods. All analyses were run through the SPSS version 23.

\section{Findings and Discussion}

This section presents a discussion of the results of the experiment, statistical analysis and interpretation of quantitative and qualitative data. The findings of the study, analysis and interpretation of the results were based on the objectives of the study. The analysis of data was done both descriptively and inferentially and presentation of findings was done with the help of tables.

\section{Pretest Analysis}

This section was guided by one research question which sought to determine the comparability of the experimental and the control group before the intervention.

Research question 1: What is the level of achievement in mathematics by students in the experimental and control groups before the personalized learning picked up?

It is important to ascertain whether the groups are different before the actual experiment. This is in line with the requirement of an experimental study which requires that if a research project involves a treatment, intervention or some kind of experimental manipulation, one needs to consider using a pre-test/post-test design (known more generally as a repeated-measures design), where the same participants are measured on the variables of interest in at least two points in time (Bonnell, Alatishe, \& Hofner, 2014).

Table 2 shows the descriptive statistics in terms of the mean, standard deviation and the number of participants in the experimental and control groups. The achievement before personalized learning yielded a mean of 51.05 and a standard deviation of 12.407 for the experimental group, and a mean of 50.10 and a standard deviation of 15.771 for the control group. 
Table 2: Level of Achievement before Experimentation

\begin{tabular}{lllllll}
\hline & Experimental grouping & $\mathrm{N}$ & Mean & Std. Deviation & Mean Rank & Sum of Ranks \\
\hline Pretest scores & Experimental group & 20 & 51.05 & 12.407 & 20.43 & 408.50 \\
& Control group & 20 & 50.10 & 15.771 & 20.58 & 411.50 \\
\hline
\end{tabular}

Table 3: Mann-Whitney Test

\begin{tabular}{lc}
\hline & Pretest scores \\
\hline Mann-Whitney U & 198.500 \\
Wilcoxon W & 408.500 \\
Z & -.041 \\
Asymp. Sig. (2-tailed) & .968 \\
\hline
\end{tabular}

To determine if the difference in scores is significant, Mann-Whitney $U$ test was used and the results are displayed in table 3 .

From table 3 , the p-value of 0.968 is greater than 0.05 , which was the set level of significance. The difference between the pretest scores of the experimental group and the control group is therefore not significant. The finding shows that the levels of achievement in mathematics of the students in the experimental and control groups before personalized learning picked up were comparable.

\section{Posttest Analysis}

This section sought to determine the comparability of the experimental and control groups after the intervention.

Table 4: Comparison of the Mathematics Achievement of Students in Experimental and Control Groups

\begin{tabular}{lllllcc}
\hline & & & & & Sum & of \\
& Experimental grouping & $\mathrm{N}$ & Mean & Std. Deviation & Mean Rank & Ranks \\
\hline Posttest scores & Experimental group & 20 & 74.15 & 12.713 & 20.60 & 412.00 \\
& Control group & 20 & 68.95 & 23.809 & 20.40 & 408.00 \\
\hline
\end{tabular}

Table 5: Mann-Whitney Test Statistics

\begin{tabular}{lr}
\hline & Posttest scores \\
\hline Mann-Whitney U & 198.000 \\
Wilcoxon W & 408.000 \\
Z & -.054 \\
Asymp. Sig. (2-tailed) & .957 \\
\hline
\end{tabular}

Research question 2: Is there a significant difference between the mathematics achievement of students in the experimental and control groups after the intervention?

Table 4 and 5 show the group descriptive statistics and the test of difference in achievement of the experimental and control groups. From the tables, the posttest means of the experimental group (74.15) is numerically higher than that of the control group (68.95). However, due to the $p$-value is 0.957 which is greater than 0.05 , the set level of significance, the difference between the posttest scores of the experimental group and the control group is not significant. This implies that the implementation of personalized learning in the experimental group did not make a significant difference in the students' mathematics achievement. This could be attributed to small sample size and the teacher- student factors such as inadequate time to cope with the syllabus demands, in addition to implementing the new learning strategy. From the videos observed it could be seen that the teacher had to balance between implementing the Personalized Learning components as well as meeting the syllabus set objectives. Learners also found it hard to adopt the 
new style as majority were deeply rooted in the traditional methods of learning.

According to Pane et al. (2017), much of the difference is likely to take place due to different study samples. In this study the school, teacher and even students were relatively new to implementing $P L$, resulting to non-significance as the full effects of $\mathrm{PL}$ take some time to emerge. The benefits suggested by two-year analyses suggest that effects are more positive after schools have at least one year of experience in implementing PL. It is not yet clear how the effects will accumulate over longer durations, as schools and students gain experience with this major change to schooling. As the field matures with greater understanding of effective PL strategies and more complete packages of curriculum materials and supports, larger and moreconsistent positive effects may be possible (Steiner, Hamilton, Peet, \& Pane, 2015).

The results are also supported by Bates and Wiest (2004), who allude to the fact that the possible reasons of no increment in students' achievement were a) the solutions which were provided by personalization could not be covered by the reasons of the situation that students could not solve word problems, b) age of students, c) treatment which does not include personalized instruction practices. Furthermore, majority of the students could not properly understand the word problems as English was a barrier. This was seen in the post test results of the two students, one from Kenya and the other from Tanzania, in the control class who dismally performed in the posttest exams.

Comparing the pretest and posttest scores of both groups, the experimental group improved its mean scores from 51.05 to 74.15 (an increase of 23.1) while the control group improved from 50.10 to 68.95 (an increase of 18.85). This implies that although personalized learning seemed not to have impacted much on learning as shown by the fact that the difference in the mean scores was not statistically significant, it still has a great potential in improving students' achievement in mathematics, since it yields better test scores than the traditional methods. The findings suggest that personalized learning (PL) can improve achievement for students, regardless of their starting level of achievement. Further, the benefits of PL may take some time to emerge and that its effect may be more positive after schools have had a longer experience with its implementation.

\section{Comparison of Achievement by Gender}

It was necessary to test the achievement according to gender as reflected in the next research question.

Research question 3: Does the mathematics achievement of students taught using personalized learning differ significantly for male and female students?

Table 6 shows the group statistics and the test of difference in achievement by male and female students in the experimental group.

Although the posttest mean score of the male students (76.82) is numerically higher than that of the female students (70.89) in the experimental group, the p-value of 0.594 is greater than 0.05 , the set level of significance, thus the difference between the posttest scores of the male and female students in the experimental group is not significant. This implies that the implementation of personalized learning in the experimental group did not make a difference in the mathematics achievement of male and female students. Therefore, PL can improve achievement for students, regardless of gender.

Table 6 further gives a comparison of the means and the mean difference between pretest and posttest of both the male and females in the experimental class. A keen look at the results indicates that both boys and girls benefited equally from personalized learning and that achievement basically depended on an individual student and not gender.

Table 6: Comparison of Pretest and Posttest Scores of Males and Females

\begin{tabular}{lccc}
\hline Gender & Pre-test mean & Post-test mean & Mean Difference \\
\hline Female & 46.44 & 70.89 & 24.37 \\
Male & 54.81 & 76.82 & 22.01 \\
\hline
\end{tabular}

This is in line with the study done by Bates and Wiest (2004), which found out that personalization did not affect the achievement and there were no significant differences between genders, besides the fact that students' opinions were positive. Moreover, Şimşek and Çakır (2009) found no 
significant difference between genders. Therefore, the personalized teaching strategy has similar effect on both male and female students.

\section{Implementation of Personalized Learning}

This section presents analysis and interpretation of data regarding the rates of personalized learning as reflected in the next research question.

Research question 4: To what extent was the personalized learning implemented in the experimental group?

The questionnaire measuring the extent of the implementation of the personalized learning in the experimental group used a four-point scale. The scale (level of agreement) was interpreted in a range of 1-4 where $1.00-1.49$ represented disagree (low level), $1.50-2.49$ represented tend to disagree (below average level), $2.50-3.49$ represented tend to agree (average level) and $3.50-4.00$ represented agree (high level).

\section{Flexible content, tools and learning environment}

As indicated in table 7, students agreed that they are allowed to do a lot of practice on their work (3.65). They also tended to agree that teachers brought books and mathematical instruments that aided their learning (3.15), that teachers used their assignments result to inform and modify what to teach (3.25), that students were guided to learn at their pace (3.30), that teachers assigned them to revise specific topics based on their needs (2.95), that teachers organize time for them to be in the library to do their personal studies (2.65) and that teachers kept on changing learning rooms (use of optional classes) for proper content delivery (2.80). On the other hand, students tended to disagree that teachers frequently changed books and teaching instruments according to students' needs and interest (2.40) used different books to facilitate understanding and application of knowledge (2.05) and kept on changing the discussion groups per every lesson (2.35).

The findings had an overall mean of 2.86 and a standard deviation of 0.645 which is a low standard deviation indicating that majority of the respondents tended to agree on experiencing personalized instruction. This means that flexible content, tools and learning environment as a component of personalized learning were experienced. The implementation was good, particularly, in the cases where the teacher used feedback on student's assignment to modify his teaching and when the teacher let student's work at their pace and practice. Areas which needed much improvement were changing discussion groups and the use of different text book for application of knowledge and skills.

Table 7: Flexible Content and Tools and Learning Environment

\begin{tabular}{lcc}
\hline \multicolumn{1}{c}{ Item in the Questionnaire } & Mean & Std. Dev \\
\hline Teacher brings books and mathematical instruments that aid my learning & 3.15 & 1.309 \\
Teacher organizes time for me to be in the library to do my personal studies & 2.65 & 1.309 \\
Teacher assigns me to revise specific topics based on my need & 2.95 & 1.356 \\
Teacher uses my assignment result to inform an modify what to teach & 3.25 & .910 \\
Teacher frequently changes books and teaching instruments according to my needs & 2.40 & 1.465 \\
and interest & 2.05 & 1.356 \\
Teacher uses different books to facilitate understanding and application of knowledge & 3.30 & 1.218 \\
I am guided to learn at my pace & 3.65 & .587 \\
I am allowed to do a lot of practice on my work & 2.35 & 1.309 \\
Teacher keeps on changing the discussion groups per every lesson & 2.80 & 1.508 \\
Teacher keeps on changing learning rooms(use of optional classes) for proper content & 2.86 & .645 \\
delivery & & 2 \\
FLEXIBLE CONTENT AND TOOLS AND LEARNING ENVIRONMENT & & \\
N $=20$ & &
\end{tabular}

According to Lippman (2010), creating an effective learning environment requires the management to subscribe to practice theory and link that to responsive commissioning. Practice theory describes the interaction between the learner and the environment. Responsive commissioning explores the nature of the interaction between the social and the physical aspects of the learning environment. In other words, to create an effective learning environment management, it is important to understand how students function in the classroom 
and how students interact with both the teacher and other students within that space.

Tanner (2008) observes that specific physical environmental factors such as environments promoting movement and circulation, large group meeting places, lighting and instructional neighborhoods are positively correlated with student achievement, even after controlling for potentially mediating variables. Further, a recent report released by the American Institutes for Research (AIR) makes this claim, naming blended learning environments as one possible way to introduce flexibility into the classroom (Tanenbaum, Le Floch, \& Boyle, 2013).

It is, however, noted that some components were not well implemented as indicated by high standard deviations in the following aspects; (1) Teacher frequently changes books and teaching instruments according to my needs and interest. This could be attributed to the shortage of the required text books for curriculum implementation, and ill equipped math's laboratory coupled with inadequate teaching models; (2) Teachers kept on changing the discussion groups per every lesson. As stated earlier, time is a major function of personalized learning. The teacher faulted in some occasions by not changing the groups as frequent as possible citing lethargy and time factor. The researcher kept on intervening on this area. It was also noted that this was a new idea and the teacher was struggling to adopt it within the shortest time possible, which led several lapses on implementation.

\section{Targeted Instruction}

As presented in table 8 , students agreed that teachers reviewed their assignments to identify their needs (3.60) and adjusted teaching styles for each group of students based on the student needs (3.60). Students tended to agree that teachers give direction on syllabus requirements (3.05), students work report is used to create students' groups based on interest, needs and skill level (2.65). Students also tended to disagree that their discussion groups are changed with some frequency (2.35) and their work is used as an integral part of daily interaction (2.25).

The findings had a mean of 2.92 and a standard deviation of 0.691 which is a low standard deviation meaning majority of the respondents tended to agree that teachers target instructional needs of an individual learner. However, the high standard deviations noted on the items on student work report, frequency of change of discussion groups, daily interactions and syllabus requirements shows that in some occasions the learning method was not fully implemented in the experimental class. This could be attributed to time restraints and focus on curriculum content and standards.

Table 8: Targeted Instruction

\begin{tabular}{lcc}
\hline \multicolumn{1}{c}{ Item in the Questionnaire } & Mean & Std. Deviation \\
\hline Teacher reviews my assignments to identify my needs & 3.60 & .940 \\
Teacher adjusts teaching style for each group of students based on the & 3.60 & .940 \\
student need & & 1.089 \\
Students work report is used to create students groups based on interest, & 2.65 & 1.309 \\
needs and skill level & 2.35 & 1.333 \\
Our discussion groups are changed with some frequency & 2.25 & 1.234 \\
My work is used as an integral part of daily interaction & 3.05 & .691 \\
Teacher gives direction on syllabus requirements & 2.92 & \\
TARGETED INSTRUCTION & & \\
$\mathrm{N}=20$ & &
\end{tabular}

As observed by Richburg-Burgess (2012), targeted instruction which involves teacher reviewing student data to identify instructional needs of students, grouping students in homogenous or heterogeneous formats based on skill-level, modifying delivery of instruction for each group of students based on student need; breaking down the whole-group structure of traditional classrooms, and teacher flexibility in what and when to teach helps to meet the needs of all students and spur their growth.

\section{Student reflection and ownership}

As indicated on table 9, students agreed that teacher guided them on revisiting their work (3.80), teachers met with them individually to listen and develop relationship with them (3.60) and they were allowed to make choices on the structure of 
learning (3.55). Students tended to agree that teachers provided them with some form of choice in assignments (3.00), teachers provided them with choice in prioritization of tasks or path to complete assignments (3.05), they are allowed to create their own daily priorities (3.00) and they are allowed to make choices about the content guided by the syllabus (3.35). However, students tended to disagree that teachers set time during the day for one-on-one academic support (2.35). This could be attributed to time restraint which resulted to inadequate implementation.

Table 9: Student Reflection and Ownership

\begin{tabular}{lcc}
\hline \multicolumn{1}{c}{ Item in the Questionnaire } & Mean & Std. Deviation \\
\hline Teacher guides me on revisiting my work & 3.80 & .523 \\
Teacher meets with me individually to listen and develop relationship & 3.60 & .940 \\
with me & 3.00 & 1.076 \\
Teacher provides me with some form of choice in assignment & 3.05 & 1.146 \\
Teacher provides me with choice in prioritization of tasks or path to & 3.00 & 1.076 \\
complete assignments & 3.35 & 1.040 \\
I am allowed to create my own daily priorities & 3.55 & .759 \\
I am allowed to make choices about the content guided by the syllabus & 2.35 & 1.309 \\
I am allowed to make choices on the structure of learning & 3.21 & .490 \\
Teacher sets time during the day for one-on-one academic support & & \\
STUDENT REFLECTION AND OWNERSHIP (STUDENT CHOICE) & \\
N = 20 & & \\
\hline
\end{tabular}

The result had a mean of 3.21 which means tend to agree and a standard deviation of 0.490 which is a low standard deviation meaning majority of the respondents tended to agree that students are allowed to reflect and own the learning process. It is however noted that the teacher could not fully get time to implement areas that demand a lot of time including: interaction on one on one basis with the learners, provision of choice to the students, matters of prioritization and matters of choice making. These could be alluded to extraneous circumstances such as time factor and congested curriculum resulting to a greater standard deviation.

According to Perks (2010), student choice is the practice of giving learners the ability to make choices about what they are learning in the classroom with the intention of boosting their engagement and motivation. By enhancing student engagement, teachers hope that they will be able to influence student achievement and generate positive outcomes.

The findings of the study are in agreement with Patall, Cooper, and Wynn (2010) who posit that learners with a choice in their homework assignments exhibit increased interest in, enjoyment of, and competency in homework. Moreover, choice does have a measurable impact on students' achievement as students perform better on end-of-unit tests when presented with options in completing homework. According to Next Generation Learning Challenges, an organization dedicated to enhancing college and career readiness through technological innovation, competency-based learning allows students to move at their own optimal pace and receive credit when they demonstrate mastery of the material (Vogt, 2017).

In totality, there is suggestive evidence that proper implementation of PL practices may be related to more-positive effects on achievement; the findings shows evidence on which practices are most effective or what policies must be in place to maximize the benefits. Further, it was noticeable that all participants could describe or identify strengths of personalized learning in their mathematics class. It was evident that all participants struggled with the fact that despite knowing the benefits of personalized learning, teachers still were not using this as an ongoing teaching approach in mathematics.

\section{Conclusion and Recommendations}

Based on findings in this study, this section presents the conclusions and corresponding recommendations.

\section{Conclusions}

Personalized learning can have an influence on achievement in mathematics if proper implementation is done and factors such as resources, manpower, time and methodology are given prime consideration. It is also concluded that personalized learning has equal bearing on 
achievement in mathematics regardless of the gender. Finally, benefits of personalized learning may take some time to emerge.

\section{Recommendations}

It is recommended that mathematics teachers be trained in the implementation of personalized learning. There is a need to conduct further research on the effects of personalized learning on students' mathematics achievement involving a large sample of students for at least one school term.

\section{Reference}

Babayemi, J. O., \& Olagunju, A. M. (2015). A survey of pre-service teachers' skills for improvising educational resources for effective instruction in basic science. African Journal of Educational Research (AJER), 19(1 \& 2), 64-76.

Bates, E. T., \& Wiest, L. R. (2004). Impact of personalization of mathematical word problems on student performance. The Mathematics Educator, 14(2), 17-26.

Bolstad, R., Gilbert, J., McDowall, S., Bull, A., Boyd, S., \& Hipkins, R. (2012). Supporting future oriented learning and teaching - a New Zealand perspective. New Zealand: Ministry of Education.

Bonnell, W., Alatishe, Y. A., \& Hofner, A. (2014). The effects of a changing culture on a child and adolescent psychiatric inpatient unit. Journal of the Canadian Academy of Child and Adolescent Psychiatry, 23(1), 65-69.

Criticos, C. (2000). Experiential learning and social transformation for a post-apartheid learning future. In D. Boud, R. Cohen, \& D. Walker (Eds.) Using experience for learning (pp. 159-165). Milton Keynes, England: SRHE.

Deakin Crick, R. (2007). Learning how to learn: The dynamic assessment of learning power. The Curriculum Journal, 18(2), 135-153.

De Freitas, S., \& Yapp, C. (Eds.). (2005). Personalizing learning in the 21st century. Stafford, UK: Network Educational Press.

Demski, J. (2012). This time it's personal. THE Journal (Technological Horizons In Education), 39(1), 32-36. Available online: https://thejournal.com/Articles/2012/01/04 /Personalized-learning.aspx?

Fafunwa, A. B. (2018). History of education in Nigeria. London: Routledge.
Herlihy, C. M., \& Quint, J. (2006). Emerging evidence on improving high school student achievement and graduation rates: The effects of four popular improvement programs. (National High School Center Research Brief). Retrieved from https://files.eric.ed.gov/fulltext/ED501076.p df

Kenya National Examination Council-KNEC. (2017). KCPE examination report 2017. Nairobi: KNEC.

Lionesses of Africa. (n. d.). Rapelang Rabana, founder of rekindle learning. Retrieved from http://www.lionessesofafrica.com/lionessrapelang-rabana

Lipman, P. (2010). Bringing out the best in them: The contribution of culturally relevant teachers to education. Theory into Practice, 34(3), 203-208.

McLeskey, J. L., Rosenberg, M. S., \& Westling, D. L. (2017). Inclusion: Effective practices for all students. Pearson.

Mertler, C., \& Charles, C. M. (2008). Introduction to educational research. London: Pearson.

Osadebe, P. U., \& Nwabeze, C. P. (2018). Construction and validation of physics aptitude test as an assessment tool for senior secondary school students. International Journal of Assessment Tools in Education, 5(3), 461-473. DOI:10.21449/ijate.442406

Pane, J. F., Steiner, E. D., Baird, M., Hamilton, L. S., \& Pane, J. D. (2017, July). Informing progress: Insights on personalized learning implementation and effects. (RAND Corporation Research Report). Retrieved from

https://www.rand.org/pubs/research_repor ts/RR2042.html

Papadakis, S., \& Kalogiannakis, M. (2017). Mobile educational applications for children: what educators and parents need to know. International Journal of Mobile Learning and Organisation, 11(3), 256-277.

Patall, E. A., Cooper, H., \& Wynn, S. R. (2010). The effectiveness and relative importance of choice in the classroom. Journal of Educational Psychology, 102, 896-915. doi:10.1037/a0019545

Perks, K. (2010). Crafting effective choices to motivate students. Adolescent Literacy in Perspective, 2, 2-15. 
Prain, V., Cox, P., Deed, C., Dorman, J., Edwards, D., Farrelly, C., ... Yager, Z.

(2013). Personalised learning lessons to be learnt. British Educational Research Journal, 39(4),

654-676.

https://doi.org/10.1080/01411926.2012.669747

Rajendran, R., \& Muralidharan, A. (2013, December). Impact of mindspark's adaptive logic on student learning. Paper presented at IEEE Fifth International Conference on Technology for Education (T4E), Kharagpur, India.

Richburg-Burgess, J. (2012). Targeted instruction for struggling readers: It takes a team. Dissertation available from ProQuest. https://repository.upenn.edu/dissertations/ AAI3530073

Schutt, R. K. (2017). Understanding the social world: Research methods for the $21^{\text {st }}$ century. Los Angeles, CA: Sage Publications. Retrieved from

https://www.sagepub.com/sites/default/file s/upm-binaries/77685_Chapter_8.pdf

Shuttleworth, M. (2008). Quantitative research design. Retrieved from https://explorable.com/quantitativeresearch-design

Şimşek, N., \& Çakır, Ö. (2009). Effect of personalization on students 'achievement and gender factor in mathematics education. International Journal of Social Sciences, 4(4), 278-282.
Steiner, E. D., Hamilton, L. S., Peet, E. D., \& Pane, J. D. (2015, November). Continued progress: Promising evidence on personalized learning. (RAND Corporation Research Report). Retrieved from https://www.rand.org/pubs/research_repor ts/RR1365z2.html

Tanenbaum, C., Le Floch, K., Boyle, A. (2013). Are personalized learning environments the next wave of $\mathrm{K}-12$ education reform. (Education issue paper series). Retrieved from http://www. air. org/sites/default/files/AIR_Personalized_ Learning_Issue_Paper_2013. pdf.

Traxler, J. (2018). Learning with mobiles: The global south. Research in Comparative \& International Education, 13(1), 152-175. DOI: $10.1177 / 1745499918761509$

Vogt, K. (2017, January). When projects are personalized, learning is social. Education Week. Retrieved from http://blogs.edweek.org/edweek/learning_ deeply/2017/01/when_projects_are_person alize d_learning_is_social.html

Yara, P. O., \& Otieno, K. O. (2010). Teaching/learning resources and academic performance in mathematics in secondary schools in Bondo district of Kenya. Asian Social Science, 6(12), 126-132. DOI: $10.5539 /$ ass.v6n12p126 